\title{
PORT RISK ASSESSMENT METHODOLOGY FOR HUMAN ACCIDENTS IN CONTAINER TERMINALS: EVIDENCE FROM THE PORT OF PIRAEUS - GREECE
}

\section{Constantinos I. Chlomoudis ${ }^{1}$, Petros L. Pallis ${ }^{2}$, Ernestos S. Tzannatos ${ }^{3}$}

1,2,3 Department of Maritime Studies, University of Piraeus, Piraeus, Greece

Received 12 October 2016; accepted 17 November 2016

\begin{abstract}
World trade increasingly relies on longer, larger and more complex port systems, where maritime transportation is a vital backbone of such operations. Port systems are more prone to being risk oriented. Many specific methods have been found to assess risk and safety in a port area or operation. A review is presented of different approaches to quantify the risk in port area. On the other hand, there is no specific risk assessment method or framework to cope with threats and hazards as a whole.

This conceptual paper presents a Port Risk Assessment (PRA) methodology, seeking to transfer the Formal Safety Assessment (FSA) framework as applied to ships into the domain of ports. The PRA is structured to include all steps from risk identification and assessment to risk control cost/benefit assessment and recommendation, and is capable of modelling all probable port risks on human lives, property and the environment.
\end{abstract}

The applicability of the PRA is demonstrated for human accidents with reference to the container terminal of the Port of Piraeus, in Greece.

Keywords: Ports, Risk Assessment, Human Accidents, Container Terminals, Empirical Evidence, Greece.

\section{Introduction}

The port industry is one of the business sectors facing significant threats, which increase the risk taken by both investors and stakeholders in general. Managing such risks is an object of research (Chlomoudis and Pallis, 2008). Managers incorporate risk analysis in their decision-making process and the adaptations of risk analysis and management by maritime discipline, along with its deployment in the port industry and government agencies in decisionmaking (Chlomoudis et al., 2005) have led to an unprecedented development of theory, methodology, and practical tools (Chlomoudis et al., 2013).

Risk has been considered as the chance that someone or something that is valuated will be adversely affected by the hazard (Woodruff, 2005), while "hazard" is any unsafe condition or potential source of an undesirable event with potential for harm or damage (Reniers et al., 2005). Moreover, risk has been defined as a measure under uncertainty of the severity of a hazard (Høj and Kröger, 2002), or a measure of the

${ }^{3}$ Corresponding author: et@unipi.gr 
probability and severity of adverse effects (Haimes, 2009). In general, “danger” should be defined as an attribute of substances or processes, which may potentially cause harm (Høj and Kröger, 2002).

Risk assessment is an essential and systematic process for assessing the impact, occurrence and the consequences of human activities on systems with hazardous characteristics (Van Duijne et al., 2008) and constitutes a needful tool for a safety policy.

The diversity in risk analysis procedures is such that there are many appropriate techniques for any circumstance and the choice has become more a matter of taste (Reniers et al., 2005; Rouvroye and Van Den Bliek, 2002).

The main objective of this work is to develop a risk based methodology suitable for ports through an adaptation of the FSA approach as applied in other cases of maritime interest (Tzannatos and Xirouchakis, 2013; Skjong et al., 2005), whilst utilizing the knowledge and experience gained through other workrelated risk analysis and assessment (RAA) methods and techniques (Marhavilas et al., 2011).

In meeting this objective, the container terminal of the Port of Piraeus by virtue of its throughput performance is considered a suitable and representative reference for demonstrating the applicability of the proposed Port Risk Assessment (PRA), through contacting an empirical study on encountered accidents during 2008-2011.

\section{Port Risk Assessment Methodology. Evidence from Container Terminal of Piraeus}

\subsection{PRA Structure}

While it is generally accepted that the overall level of maritime safety has improved in recent years, further and ongoing improvements are still desirable. The safety culture of anticipating hazards rather than waiting for accidents to reveal them has been widely used in many industries. The international shipping industry has begun to move from a reactive to a proactive approach to safety through what is known as Formal Safety Assessment (FSA). (Chlomoudis et al., 2012)

Such a methodological framework, which investigates and undertakes shipping related risks as a whole, has been lacked from the port industry. Our research scope, through Port Risk Assessment (PRA) is to adapt from shipping industry to port industry a wellestablished and effective methodological framework in order to develop proactive safety processes and regulations into the port context.

Although the Port Risk Assessment (PRA) maintains the basic number of steps involved in the structure of the Formal Safety Assessment (FSA), their content is modified to address the port- specific (as opposed to the FSA ship-specific) issues of risk commencing with the preliminary step of "System Identification" and following all subsequent steps as presented in Table 1 . 
Table 1

Structure of PRA: Steps \& Processes

\begin{tabular}{|c|c|c|}
\hline Step & Step Feature & Step Content \\
\hline 0 & System Identification & Port; Container Terminal \\
\hline 1 & Risk Identification & $\begin{array}{c}\text { What may go wrong and which port functions/capabilities } \\
\text { should be protected }\end{array}$ \\
\hline 2 & Risk Assessment & Investigation/quantification of most important port risks \\
\hline 3 & Risk Control Options & $\begin{array}{c}\text { Measures to mitigate most important port risks and measures to } \\
\text { restore port functions/capabilities }\end{array}$ \\
\hline 4 & Cost/Benefit Assessment & Cost/benefit assessment of port risk control measures \\
\hline 5 & Decision Making & Recommendation and feedback to assessment - Port Risk Index \\
\hline
\end{tabular}

Source: Authors

\subsection{Risk Identification}

With the port being identified as the system of interest, risk identification is the first and in many ways the most important step in risk assessment. An overlooked risk is likely to introduce more error into the overall risk estimate than an inaccurate consequence model or frequency estimate. Therefore, the aim of risk identification is to produce a comprehensive list of all risks (Trbojevic and Carr, 2000). Investigating historical data on previous incidents is typically the first step, in addition to structured brainstorming sections with practitioners for conceivable risks. Taking into account the limitation of resources, a typical approach involves the screening of risks in order to identify those which should be targeted on the basis of the combined influence of their frequency of occurrence and their consequences (Berle et al., 2011).

The initial taxonomy of risks for human accidents developed (Table 2) was based on the literature review and included the main risk categories for port container terminals at an international level. It should be noted that the term "taxonomy" is used to refer to a polyhierarchical classification in which individual components may appear more than once.

Table 2

Risks for Human Accidents in Port Container Terminal of Piraeus

\begin{tabular}{|c|c|}
\hline \multirow{4}{*}{ Risk } & Risk Categories \\
\hline \multirow{4}{*}{ Human Accidents } & Ship collisions \\
\cline { 2 - 2 } & Grounding \\
\cline { 2 - 2 } & Sinking \\
\cline { 2 - 2 } & Navigation error \\
\cline { 2 - 2 } & Pilotage error \\
\cline { 2 - 2 } & Poor maintenance \\
\cline { 2 - 2 } & Falling of a crane \\
\cline { 2 - 2 } & Falling of a Container \\
\cline { 2 - 2 } & Error in Cargo handling and storage \\
\hline
\end{tabular}

Source: Chlomoudis et al., 2012 


\subsection{Risk Assessment}

Risk can be quantitatively and qualitatively assessed by the use of a risk matrix
(Table 3) in which the rows represent the increasing severity of consequences of a released risk and the columns represent the increasing likelihood or frequency of these consequences.

\section{Table 3}

Risk Matrix

\begin{tabular}{|c|c|c|c|c|c|}
\hline \multirow{2}{*}{\multicolumn{2}{|c|}{ Frequency (FI) }} & \multicolumn{4}{c|}{ Severity (SI) } \\
\cline { 3 - 6 } & & 1 & 2 & 3 & 4 \\
\cline { 3 - 6 } & Frequent & Minor & Significant & Severe & Catastrophic \\
\hline 7 & & 8 & 9 & 10 & 11 \\
\hline 6 & & 7 & 8 & 9 & 10 \\
\hline 5 & Reasonable Possible & 6 & 7 & 8 & 8 \\
\hline 4 & & 5 & 6 & 7 & 7 \\
\hline 3 & Remote & 4 & 5 & 5 & 6 \\
\hline 2 & & 3 & 4 & 4 & 5 \\
\hline 1 & Extremely remote & 2 & 3 & 5 & 8 \\
\hline
\end{tabular}

Source: Authors

The quantification of the risk is performed through the summation of frequency (FI) and severity (SI) indices which express various levels of corresponding significance, as shown in Tables 4 and 5 respectively.

\section{Table 4}

Frequency Index (FI)

\begin{tabular}{|c|c|c|c|}
\hline FI & Frequency & Definition & F (per Year) \\
\hline 7 & Frequent & Likely to occur once per day & 10 \\
\hline 5 & Reasonable Possible & Likely to occur once per month & 0.1 \\
\hline 3 & Remote & Likely to occur once per year & 0.01 \\
\hline 1 & Extremely remote & Likely to occur once in a life time & \\
\hline
\end{tabular}

Source: Adapted by IMO FSA

\section{Table 5}

Severity Index (SI)

\begin{tabular}{|c|c|c|c|}
\hline SI & Severity & Effects on Human Safety & S (Equivalent Fatalities) \\
\hline 1 & Minor & Single or minor injuries & 0.01 \\
\hline 2 & Significant & Multiple or severe injuries & 0.1 \\
\hline 3 & Severe & $\begin{array}{c}\text { Single fatality or multiple } \\
\text { severe injuries }\end{array}$ & 1 \\
\hline 4 & Catastrophic & Multiple fatalities & 10 \\
\hline
\end{tabular}

Source: Adapted by IMO FSA

The previous initial taxonomy has been incorporated into interview forms of a second stage procedure. In support of the interviews, an initial consultation with port container personnel took place and the container terminal director of the port of
Piraeus (OLP operated container terminal) agreed to participate in the research, by completing a specially designed interview form. The director of the container terminal of Piraeus, gave the following prioritization for the human accidents. 


\section{Table 6}

Risk Assessment for Human Accidents in Port Container Terminal of Piraeus

\begin{tabular}{|c|c|c|c|c|}
\hline A/A & Risks & Frequency & Severity & Risk Assessment \\
\hline 1st & Falling of a Container & 3 & 4 & 12 \\
\hline 2nd & Poor maintenance & 3 & 3 & 9 \\
\hline 3rd & Error in Cargo handling and storage & 3 & 2 & 6 \\
\hline 4th & Pilotage error & 2 & 3 & 6 \\
\hline 5th & Falling of a crane & 2 & 2 & 4 \\
\hline 6th & Ship collisions & 2 & 1 & 2 \\
\hline 7th & Sinking & 1 & 1 & 1 \\
\hline 8th & Navigation error & 1 & 1 & 1 \\
\hline 9th & Grounding & 1 & 1 \\
\hline
\end{tabular}

Source: Chlomoudis et al., 2012.

Moreover, the Director of the Piraeus container terminal gave a very high priority for prevention and high priorities in the preparedness and the reaction and medium significance in recovery. Finally, very high importance was given to preventive maintenance and employee training, high importance to ship/cargo monitoring and quality/safety assurance, while low importance in security measures and guards. Additionally, in an effort to demonstrate the validity of the proposed Port Risk Assessment (PRA) through a workable example, we obtained the historical data (2008-2012) of "incidents" involving human injuries in the container terminal of Piraeus, as shown in Table 7.

Table 7

Consequences of Human Accidents (2008 - 2012)

\begin{tabular}{|c|c|c|c|c|c|c|c|}
\hline Month & Injury Severity & 2008 & 2009 & 2010 & 2011 & 2012 & Total \\
\hline \multirow{4}{*}{ January } & Minor & 1 & 1 & 3 & & 2 & 7 \\
\hline & Significant & & & & & & 0 \\
\hline & Single Fatality & & & & & & 0 \\
\hline & Total & 1 & 1 & 3 & 0 & 2 & 7 \\
\hline \multirow{4}{*}{ February } & Minor & & 1 & 1 & & 1 & 3 \\
\hline & Significant & & & & & & 0 \\
\hline & Single Fatality & & & & & & 0 \\
\hline & Total & 0 & 1 & 1 & 0 & 1 & 3 \\
\hline \multirow{4}{*}{ March } & Minor & 1 & & 1 & 1 & & 3 \\
\hline & Significant & & 1 & & & & 1 \\
\hline & Single Fatality & & & & & & 0 \\
\hline & Total & 1 & 1 & 1 & 1 & 0 & 4 \\
\hline \multirow{4}{*}{ April } & Minor & 2 & 2 & 1 & 1 & & 6 \\
\hline & Significant & & & 1 & & 1 & 2 \\
\hline & Single Fatality & & & & 1 & & 1 \\
\hline & Total & 2 & 2 & 2 & 2 & 1 & 9 \\
\hline \multirow{4}{*}{ May } & Minor & 1 & & & 1 & 1 & 3 \\
\hline & Significant & & & & & 1 & 1 \\
\hline & Single Fatality & & & & & & 0 \\
\hline & Total & 1 & 0 & 0 & 1 & 2 & 4 \\
\hline \multirow{4}{*}{ June } & Minor & 1 & & 1 & 1 & & 3 \\
\hline & Significant & & & 1 & & & 1 \\
\hline & Single Fatality & & & & & 2 & 2 \\
\hline & Total & 1 & 0 & 2 & 1 & 2 & 6 \\
\hline
\end{tabular}




\begin{tabular}{|c|c|c|c|c|c|c|c|}
\hline Month & Injury Severity & 2008 & 2009 & 2010 & 2011 & 2012 & Total \\
\hline \multirow{4}{*}{ July } & Minor & 2 & 1 & 2 & & 3 & 8 \\
\hline & Significant & & & & 1 & & 1 \\
\hline & Single Fatality & & & & & & 0 \\
\hline & Total & 2 & 1 & 2 & 1 & 3 & 9 \\
\hline \multirow{4}{*}{ August } & Minor & & & 1 & & & 1 \\
\hline & Significant & 2 & & & 1 & 1 & 4 \\
\hline & Single Fatality & & & 1 & & & 1 \\
\hline & Total & 2 & 0 & 2 & 1 & 1 & 6 \\
\hline \multirow{4}{*}{ September } & Minor & 1 & 1 & & 1 & 2 & 5 \\
\hline & Significant & 2 & & 1 & & & 3 \\
\hline & Single Fatality & 1 & & & & & 1 \\
\hline & Total & 4 & 1 & 1 & 1 & 2 & 9 \\
\hline \multirow{4}{*}{ October } & Minor & 1 & & & & 2 & 3 \\
\hline & Significant & 1 & & & & 1 & 2 \\
\hline & Single Fatality & & & & & & 0 \\
\hline & Total & 2 & 0 & 0 & 0 & 3 & 5 \\
\hline \multirow{4}{*}{ November } & Minor & & 1 & & & 2 & 3 \\
\hline & Significant & & & & 1 & & 1 \\
\hline & Single Fatality & & & & & & 0 \\
\hline & Total & 0 & 1 & 0 & 1 & 2 & 4 \\
\hline \multirow{4}{*}{ December } & Minor & & & & 1 & & 1 \\
\hline & Significant & & & & & & 0 \\
\hline & Single Fatality & & & 1 & & & 1 \\
\hline & Total & 0 & 0 & 1 & 1 & 0 & 2 \\
\hline \multirow{6}{*}{ Overall } & Severity & 2008 & 2009 & 2010 & 2011 & 2012 & Total \\
\hline & Minor & 10 & 7 & 10 & 6 & 13 & 46 \\
\hline & Significant & 5 & 1 & 3 & 3 & 4 & 16 \\
\hline & Single Fatality & 1 & 0 & 2 & 1 & 2 & 6 \\
\hline & Overall Total & 16 & 8 & 15 & 10 & 19 & 68 \\
\hline & $\begin{array}{c}\text { Equivalent Single } \\
\text { Fatalities }\end{array}$ & \multicolumn{6}{|c|}{$46 \times 0.01+16 \times 0.1+6 \times 1=8.06$} \\
\hline
\end{tabular}

Source: Authors
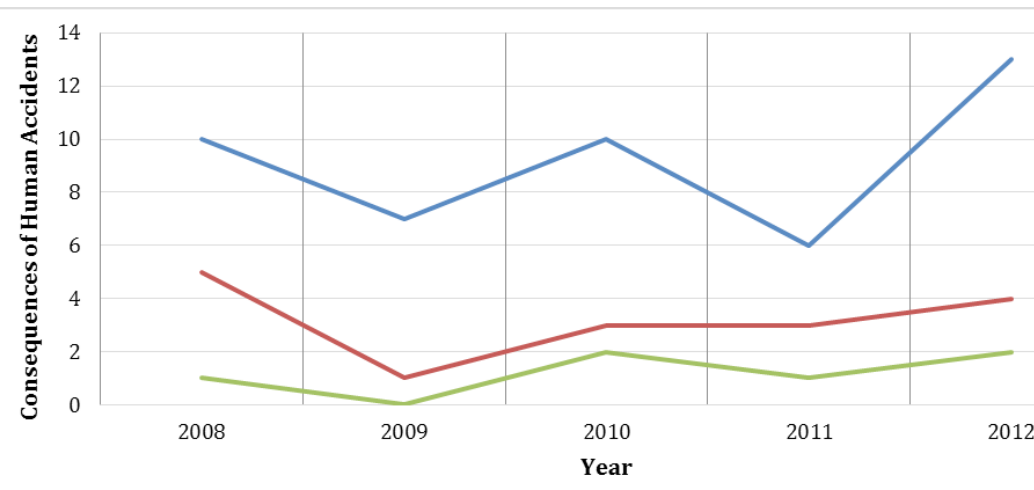

- Minor Significant $\longrightarrow$ Single Fatality

Fig. 1.

Consequences of Human Accidents (2008 - 2012)

Source: Authors 
By scaling all human injuries to single fatalities according to the severity equivalence $(S)$ shown in Table 7 and Figure 1 , the fatality rate at the container terminal of Piraeus over the period 2008-2012 is found to be equal to 1.612 fatalities per port-year.

\subsection{Risk Control Options (RCO)}

The purpose of this step is to propose economically effective Risk Control Options (RCOs). The basic task is to group risk control measures into possible RCOs. The areas, that have to be focused, are those related to high frequencies or high consequences, where the risk is intolerable.

Risk control measures, through expert meetings and decisions, are combined into potential RCOs. The criteria of grouping can vary, can be just the decision of the experts or can be the fact that risk control measures prevent the system from the same failure or type of accident. The outcome of this step is a list of RCOs that will be analyzed in the next step for their cost and benefit effectiveness. Moreover, the risk reduction $(\Delta \mathrm{R})$ of an $\mathrm{RCO}$ is a very important parameter, because it provides a measure of the risk control obtained by each RCO, which can either reduce the risk to the acceptable level or can provide an even higher reduction rate.

Port experts' judgment, as port container personnel and the container terminal director, are employed in order to determine the proposed RCOs and estimate their risk reduction rate (\%), with the aim of mutually targeting towards the control of risk, i.e. of human consequences.

Table 8

RCOs

\begin{tabular}{|c|c|c|c|}
\hline RCO Parameter & RCO 1 & RCO 2 & RCO 3 \\
\hline Identification / Description & Training / Education Program & Quality Assurance System & 24-7 Monitoring System \\
\hline Risk Reduction Rate (\%) & 20 & 30 & 40 \\
\hline$\Delta$ C (\$/port) & 50,000 & 100,000 & 200,000 \\
\hline Expected Lifetime (years) & \multicolumn{3}{|}{} \\
\hline
\end{tabular}

Source: Authors

In an exercise which could be split into two separate tasks, port expert judgment firstly proceeded with the identification of RCO and secondly with the estimation of the risk reduction rate. In the first task, experts have to collect data from previous steps and to identify the potential measures and which of them are suitable to produce a number of possible and practical RCOs. An appropriate way to produce them is not to aggregate the opinions of all experts - using a mathematical approach - but through discussions, or using a suitable technique (e.g. Delphi), to let experts conclude on common measures (behavioral approach). A mathematical approach can provide an estimation of risk matrices and a statistical method an aggregate a common value. The concordance coefficient can be also used to in ranking of RCOs according to their risk reduction effect.

According to the aforementioned expert judgment, three distinct RCOs are proposed of increasing risk reduction rate and cost, involving a training/educational program (RCO1), a quality assurance system ( $\mathrm{RCO} 2$ ) and a 24-7 monitoring system ( $\mathrm{RCO} 3$ ). These RCOs are to be examined for a period 
of five years during which their quoted risk reduction rates can be reached and maintained through routine RCO updating and without the need to introduce major modifications. Furthermore, on this basis, the NPV cost of each RCO has been determined through an extensive market research and includes the initial investment as well as the operational expenditure involving the RCO running costs (e.g. safety personnel, training seminars etc) over the five-year period.

\subsection{RCO Economic Effectiveness}

The economic effectiveness of each Risk Control Option (RCO) is evaluated based upon: a) the Net Present Value (NPV) cost of its implementation and operation (incl. maintenance) through its lifetime $(\Delta \mathrm{C})$ and $\mathrm{b}$ ) its risk reduction $(\Delta \mathrm{R})$ over the same period.
Depending on the nature of risks addressed, the $\mathrm{RCO}$ acceptance and prioritization is weighed against the Implied Cost of Averting a Fatality (ICAF). Although many proposals exist for appropriate optimum values of ICAF no universally accepted values are currently established. However, the value of \$ 3 million as suggested for use by IMO continues to be a valid proposal (Skjong et al., 2005). Therefore for RCO acceptance and prioritization the expression ICAF $\leq$ $\Delta \mathrm{C} / \Delta \mathrm{R}$ applies with regard to risks of human consequences.

The risk reduction $(\Delta \mathrm{R})$ and the economic effectiveness $(\Delta C / \Delta R)$ of the three proposed Risk Control Options (RCOs) for the control of human risks associated with the container terminal of Piraeus are presented in Table 9, as follows:

\section{Table 9}

$\Delta R$ \& $\Delta C / \Delta R$ for Human and Environmental Damages

\begin{tabular}{|c|c|c|c|}
\hline Risk Parameter & RCO 1 & RCO 2 & RCO 3 \\
\hline $\begin{array}{c}\text { RCO Identification / } \\
\text { Description }\end{array}$ & $\begin{array}{c}\text { Training / Education } \\
\text { Program }\end{array}$ & Quality Assurance System & 24 X 7 Monitoring System \\
\hline Risk Reduction Rate (\%) & 20 & 30 & 40 \\
\hline $\begin{array}{c}\text { Human Damage } \\
\text { (fat./port-year) }\end{array}$ & \multicolumn{3}{|c|}{1.612} \\
\hline Expected Lifetime & \multicolumn{3}{|c|}{3.224} \\
\hline$\Delta \mathrm{R}$ fat./port & 1.612 & 5 years & 2.418 \\
\hline$\Delta \mathrm{C}(\$ /$ port $)$ & 50,000 & 100,000 & $62,035<3,000,000$ \\
\hline$\Delta \mathrm{C} / \Delta \mathrm{R}$ vs ICAF $(\$ /$ fat. $)$ & $31,017<3,000,000$ & $41,356<3,000,000$ & \\
\hline
\end{tabular}

Source: Authors

\subsection{Decision Making}

The recommendations for decision making should be a synthesis of the previous steps, selecting which measures to include and the identification of those Risk Control Options (RCOs) which keep risks as low as reasonable practicable.
All the proposed RCOs are found to be economically effective towards the control of human-related risks, whilst with regard to their prioritization $\mathrm{RCO} 1$ is the most effective and $\mathrm{RCO} 3$ the least effective. However, in a more realistic approach, it should be considered that RCOs are bound to have a different risk control influence with regard 
to the perspective risks. Alternatively an $\mathrm{RCO}$ may prove to be more effective over an extended period application provided the increase of RCO costs $(\Delta C)$ due to the accumulation of extra operational costs is low.

\section{Conclusion}

The proposed Port Risk Assessment (PRA) methodology builds its structure and functionality in accordance with the Formal Safety Assessment (FSA) and is adapted through the utilization of port expert judgment and existing topical literature in order to tailor its applicability within the port domain. The empirical case study of the container terminal of Piraeus in Greece provided a workable example through which the reliability of the proposed PRA was demonstrated and the factors affecting the economic effectiveness of proposed Risk Control Options (RCOs) were highlighted.

The proposed PRA methodology examined human risk incidents through a five years period of time. The main objective of our future research is to investigate the influence of other related risks, such as environmental, machinery, security and natural risks, into the overall equation of port risks. The proposed PRA methodology needs to be tested in other container terminals in Greece, across Europe and other continents, as well as in other port segments, such as passenger, car and cruising terminals in order to detect how their operational particularities may affect their existing risk profile and subsequently its control.

\section{References}

Berle, O.; Asbjørnslett, B. E.; Rice, J. B. 2011. Formal Vulnerability Assessment of a maritime transportation system, Reliability Engineering \& System Safety 96(6): 696-705.
Chlomoudis, C. I.; Kostagiolas, P. A.; Lampridis, D. C. 2005. Prospective employment of quality awards in the seaport industry: Old solution to contemporary questions. In Proceedings of the International Association of Maritime Economists (IAME) Conference 2005, Limassol, Cyprus.

Chlomoudis, C. I.; Pallis, L. P. 2008. Defining Factors for the Undertaking of Risk for Investments in the Port Industry. In Proceedings of the International Association of Maritime Economists (IAME) Conference 2008, Dalian, China.

Chlomoudis, C. I.; Kostagiolas, P. A.; Pallis, L. P. 2012. An Analysis for Formal Risk and Safety Assessments for Ports: Empirical Evidence from Container Terminals in Greece, Journal of Shipping and Ocean Engineering 2(1): 45-54.

Chlomoudis, C. I.; Lampridis, D. C.; Pallis, L. P. 2013. Quality Assurance: Providing Tools for Managing Risk in Ports, International Journal of Maritime, Trade and Economic Issues 1(1): 3-20.

Haimes, Y. Y. 2009. Risk modelling, assessment, and management, A John Wiley \& Sons, Inc. USA.

Høj, N. P.; Kröger, W. 2002. Risk analyses of transportation on road and railway from a European perspective, Safety Science 40(1-4): 337-357.

Marhavilas, P. K.; Koulouriotis, D.; Gemeni, V. 2011. Risk analysis and assessment methodologies in the work sites: On a review, classification and comparative study of the scientific literature of the period 2000-2009, Journal of Loss Prevention in the Process Industries 24(5): 477-523.

Reniers, G. L. L.; Ale, B. J. M.; Dullaert, W.; Soudan, K. 2005. Developing an external domino prevention framework: Hazwim, Journal of Loss Prevention in the Process Industries 18(3): 127-138.

Rouvroye, J. L.; Van Den Bliek, E. G. 2002. Comparing safety analysis techniques, Reliability Engineering \& System Safety 75(3): 289-294. 
Skjong, R.; Vanem, E.; Endresen, O. 2005. Risk Evaluation Criteria, SAFEDOR-D-4.5.2-2007-10-24DNV-RiskEvaluationCriteria-rev-3.0. Available from internet: <http://www.safedor.org >.

Trbojevic, V. M.; Carr, B. J. 2000. Risk based methodology for safety improvements in ports, Journal of Hazardous Materials 71(1): 467-480.

Tzannatos, E.; Xirouchakis, A. 2013. Techno-Economic Assessment of Hull-mounted Sonar for Oil-spill Risk Control, The Journal of Navigation 66(4): 625-636.
Van Duijne, F. H.; Aken, D.; Schouten, E. G. 2008. Considerations in developing complete and quantified methods for risk assessment, Safety Science 46(2): 245254.

Woodruff, J. M. 2005. Consequence and likelihood in risk estimation: a matter of balance in UK health and safety risk assessment practice, Safety Science 43(5-6): 345-353.

\section{ijtte 377}

